\title{
Atypical Adenoma
}

National Cancer Institute

\section{Source}

National Cancer Institute. Atypical Adenoma. NCI Thesaurus. Code C7559.

An adenoma characterized by increased cellularity and nuclear atypia without evidence of vascular or capsular invasion. A representative example is thyroid gland atypical follicular adenoma. 